\title{
Tackling the Issue of Credibility in Phenomenographic Interviewing to Capture Problem-Based Learning (PBL) Experience
}

\author{
Suraini Mohd-Ali* \\ Fariza Puteh-Behak \\ Noor Saazai Md Saat \\ Ramiaida Darmi \\ Haliza Harun \\ Rosni Samah \\ Universiti Sains Islam Malaysia (USIM), Bandar Baru Nilai, 71800 Negeri Sembilan, Malaysia \\ *Email suraini@usim.edu.my
}

Doi:10.5901/mjss.2016.v7n4p

\section{Abstract}

The trustworthiness of any qualitative research is frequently questioned by positivists, perhaps because their notions of validity and reliability cannot be addressed in the same way in naturalistic work although, the framework for trustworthiness in this form of work have been in existence for many years. There are four issues of trustworthiness that are central in any qualitative research paradigm namely credibility, transferability, dependability, and confirmability (Lincoln \& Guba, 1985). In this paper, the focus is on credibility issue in phenomenographic interviewing. Credibility is present when the research results mirror the view of the participants understudy. Investigating conceptions is the aim of phenomenographic researches and interview is commonly used as a tool to access people's conceptions. The goal in phenomenographic research is to study the phenomenon through the lens of the participants hence, there is a high reliance on the data from the interviews with the research participants. In light of that, the phenomenographic researchers will have to exercise caution in carrying out the interviews to ensure the credibility of the data, which reflects the voice of the participants, is taken care of. Using the data from one of the author's current research on learners' experiences in Problem-Based Learning (PBL), the author illustrates the kind of interview questions or prompts used to elicit responses and how the credibility of the data (content-related credibility, credibility of method and communicative credibility) was attained by employing five interviewing strategies: 1) begin with superficially shared topic, 2) follow up questions focusing on eliciting ideas/concepts, 3) more follow up questions to get concrete examples of the ideas/concepts, 4) the use of empathy in the interview and 5) bracketing interviewer's assumptions.

Keywords: Research Credibility, Phenomenographic interview, Problem-Based Learning (PBL)

\section{Introduction}

There is an often debate on the issue of trustworthiness of qualitative research by positivists because their concepts of validity and reliability cannot be framed in the same path as in naturalistic work. However, there are many writers on qualitative research methods have delineated how qualitative researchers can integrate measures that deal with these issues (Silverman, 2001; Lincoln \& Guba, 1985).

The aim of trustworthiness in a qualitative inquiry is to support the argument that the inquiry's findings are "worth paying attention to" (Lincoln \& Guba, 1985, p.290). There are four issues of trustworthiness that are central in any qualitative research paradigm namely credibility, transferability, dependability, and confirmability (Lincoln \& Guba, 1985). For the purpose of this paper, only the issue of credibility will be discussed. Credibility is a measure used to find out whether the research findings characterise a "credible" conceptual explication of the data taken from the research participants' original data (Lincoln \& Guba, 1985).

In phenomenographic research, a qualitative research paradigm, the issue of credibility plays a more critical role since the primary data in this kind of study rely heavily on phenomenographic interviews. The central premise of phenomenographic interviewing is engaging participants through reflection and dialogue about their experience and 
integrates practices that encourage participants to articulate their assumptions on which they base their actions. This in return stimulates reflection for both the interviewer and the participants. Careful consideration is deemed necessary here to ensure that credibility is achieved since the interviews rely primarily on co-construction of meaning between the participants and the interviewer (researcher). In addition, it is also deemed necessary to put more emphasis on the issue of credibility during interviews or data collection stage because the data obtained will determine the final conceptions of the participants. In other words, if the data has lack of credibility, no matter how rigorous the data analysis procedure, the final conceptions will not reflect the actual voice of the participants and thus, it defeats the aim of a phenomenographic research.

The focus of this paper is to illustrate the kind of data emerged by using strategies related to credibility of: a) content b) method and c) communicative-strategies during phenomenographic interviews to tackle the issue of credibility in the data collection stage using the data from one of the author's current research on learners' experiences in ProblemBased Learning (PBL). Specifically, the paper seeks to answer the following research question:

How the issue of credibility is tackled using phenomenographic interviewing strategies related to: content-related credibility, credibility of method and communicative credibility to capture learners' experiences in a Problem-Based Learning $(\mathrm{PBL})$ ?

\section{Literature Review}

\subsection{Research Trustworthiness: Credibility}

The trustworthiness in a qualitative research largely depends on harmony between the purpose of the study and the methodological aspects which includes data collection procedures, data analysis procedures and the discussions that ties everything together to report the research. There are more challenges in addressing the trustworthiness of the qualitative research as there is a rise in the number of guidelines available on the critical appraisal of the quality of such studies (Devers, 1999) and are also applicable to phenomenographic study. Trustworthiness as mentioned earlier covers four aspects: credibility, transferability, dependability, and confirmability. To meet the aim of this paper, only the aspect of credibility is discussed in relation to data collection procedure (phenomenographic interviewing) although the researcher is aware that there many other stages and aspects of the study that concerns the issue of credibility.

In the context of this research, the researcher enhanced the credibility issue by adopting self awareness and reflexivity as well as interpreative awareness to reduce the influence of the interviewer (researcher) during the interviewing process.

According to Collier-Reed, et al. (2009), in delineating the trustworthiness aspect of the internal horizon, the measure of credibility includes: a) content-related credibility, b) credibility of method and c) communicative credibility. "Content-related credibility relates to a researcher having a comprehensive grasp, or understanding, of topics related to the phenomenon under investigation" (Collier-Reed, et al., 2009, p. 7). Thus, it is seemingly important for the researcher to have all the realted knowledge on the subject matter under study so that the researcher is apt to answer the rigour in the research should there be doubts from the research community. As for the crebility of method, it is a snergy between the aim of the study, the research design and the implementation of the research (Booth 1992) which highlights the credibility needed in carrying out the methodological aspects of the research. In addition, according to Akerlind (2005), the credibility in communication can be achieved when the interviewer (researcher) has the ability to convincingly put forth his argument on a specific interpretation.

\subsection{Phenomenographic research and interviews}

Phenomenography adopts a qualitative research paradigm and aims at conceptualising the qualitatively different ways in which an experience is conceptualized, interpreted and understood by people in relation to what is around them (Marton, 1986, p. 31 also cited in Bowden, 2000, p. 2). Interviewing is one of the primary method used in phenomenographic research as the central premise of phenomenographic study is engaging participants through reflection and dialogue about their experience and integrates practices that encourage participants to articulate their assumptions on which they base their actions. This in return stimulates reflection for both the interviewer and the participants. Having to depend primarily on the co-construction of meaning between the participants and researcher, the strategies employed for interviewing need to be carefully considered since the trustworthiness of the data will be affected if otherwise happen. In a qualitative research, trustworthiness is very much emphasized as it determines the acceptance of the study by the research community. In a qualitative study, trustworthiness plays a crucial role that the research results are "worth paying attention to" (Lincoln \& Guba, 1985, p.290). There are four issues of trustworthiness that are central in any 
qualitative research paradigm namely credibility, transferability, dependability, and confirmability. For the purpose of this paper, only the issue of credibility will be discussed. Credibility is a measure to gauge how far the research data characterise a "credible" delineation of the findings from the research participants' original feedback (Lincoln \& Guba, 1985).

Phenomenographic interview falls into the qualitative interview paradigm. According to Edwards \& Holland (2013), many of the terms used in qualitative interviewing fall in these continuum: in-depth, informal, non-directed, open-ended, conversational, naturalistic, narrative, biographical, oral or life history, ethnographic and others. The terms used for any particular interview type relate to the underlying philosophy and specific approach taken to research (Mohd Ali, S., 2012). Despite the variations and common practice of using unstructured and semi-structured interviews in qualitative approaches, Mason (2006) addressed three common features:

a. A theme with some fluidity and flexibility in structure.

b. A reciprocal dialogue between or among two or more participants.

c. A situated and contextual perspective regarding knowledge with relevant contexts focused to facilitate meanings and understandings of the co-constructed or reconstructed exchanges.

Thus, phenomenographic interview adopts the qualitative interview paradigm very similar to any other qualitative interviewing. However, the difference lies in the focus of the interviewing in obtaining the data from the perspectives and voices of the research participants; through the participants' lens and not through the researcher's lens.

\section{Methodology}

This paper employs the data from a research on learners' Problem-Based Learning (PBL) experiences in a Malaysian university. The participants were 25 undergraduates with 10 graduates as focus group. In this phenomenographic research, interviews, observations and reflective notes were used as the data collection tools. Phenomenographic research paradigm is chosen for this study because it is meant to map the qualitatively different ways individuals experience a phenomenon; in this context it is to study the experience of the PBL learners.

Data was then coded and analyzed using interpretive paradigm. To meet the aim of this paper, discussion is centered on one of the data collection tools which is the interview.

The interview questions and guidelines were framed based on Ashworth \& Lucas (2000) guide which includes: empathic listening to grasp interpretation and intended meaning, using open-ended questions, prompting participants' line of reflection by allowing the interviewee to give clarifications and silencing researcher's voice and judgments.

Open Questions were the type of questions used in the interviews. Open questions are those that provide broad parameters within which interviewees can formulate answers in their own words concerning topics specified by the interviewer. In terms of the structure of the interview, an open-ended-loosely guided type of interview was conducted.

There were four primary areas of interest in this study: a) Task, b) Process, c) Teamwork and d) Productpresentation. Those four areas were the stages involved in the PBL process. The researcher used the four stages as the anchors in the phenomenographic interviews to get the learners' responses of their experiences. The 'Why' and 'How' questions followed after the participants responded to the primary questions. Based on the pilot interviews conducted by the researcher, it was apparent that interview should not have predetermined questions for two reasons (Mohd Ali, S. 2012). First, phenomenographic interviewing should be more natural and conversation-like so that the participants unfold their perceptions and stories comfortably. Second, the participants might unfold a new perspective of the phenomenon due to the flexibility to reflect on the conversation-like interviews.

To meet the requirement of getting in-depth data from the participants, two types of questions were set. The first was: open questions about the meaning of the phenomena for participants. The second was: questions asking participants for concrete examples illustrating the phenomena from their own experience. The open question was framed as: 'What does the experience mean to you?' This kind of questions were retained until all the primary anchors were covered as a way to give more rooms for the participants to reflect on the phenomenon before being asked for concrete examples. The aim of the open questions was to give participants the opportunity to initially focus on whatever aspects of the phenomenon appeared most significant to them (Mohd Ali, S. 2012). In accordance, the purpose for asking questions on illustrations was to get more clarity on specific context that the interviewer had spotted to be inadequate to add richness to the understandings of $\mathrm{PBL}$ within the context.

\section{Findings and Discussions}

In this section, the researcher reports the findings which illustrate five strategies used in terms of: a) content-related 
credibility, b) methodological credibility and c) communicative credibility, in this study, to capture the PBL learning experiences from the research participants.

Strategy 1: Begin with superficially shared topic

Strategy 2: Follow up questions focusing on eliciting ideas/concepts

Strategy 3: More follow up questions to get concrete examples of the ideas/concepts

Strategy 4: The use of empathy in the interview

Strategy 5: Bracketing interviewer's assumptions

The five strategies employed are in line with Stenfors-Hayes et al (2011) and Roulston (2010 in Figure 1) who propose that phenomenographic interview-guide often moves from action to experience. In this study, the researcher commence the interview by asking the participants to highlight the recent encounter with a classroom experience (Strategy 1) and then move gradually to more details about their learning encounters (Strategy $2 \& 3$ ).

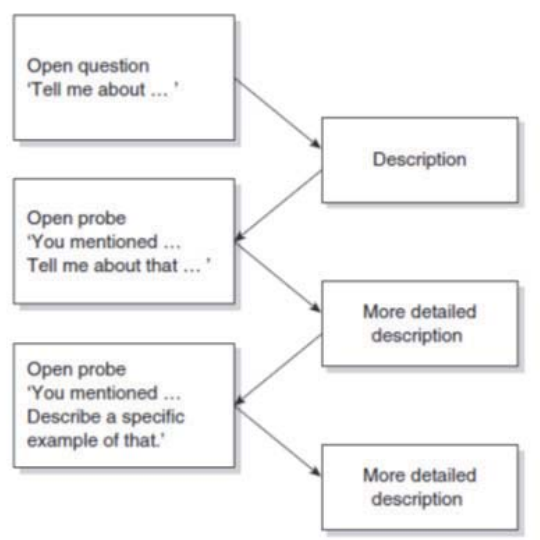

Figure 1: Probing strategies (adapted from: Roulston, 2010)

These are the excerpts from the interview transcripts to describe the type of data obtained and the ways the interviewing principles were enacted in practice.

\subsection{Strategy 1: Begin with superficially shared topic}

The primary question was: Can you share your experience in PBL2?

Excerpt 1: PBL 2 experience from Aliyah (TISUM PBL2i2)

\begin{tabular}{|c|c|l|}
\hline Line & Speaker & Dialogue \\
\hline 1 & $\mathrm{R}$ & Can you share your experience in PBL 2? \\
\hline 2 & $\mathrm{AL}$ & PBL2...mmm \\
\hline 3 & $\mathrm{R}$ & Ya... what can you say about PBL2? \\
\hline 4 & $\mathrm{AL}$ & I think it's exciting lar...[laughing] \\
\hline 5 & $\mathrm{R}$ & Ok exciting... why \\
\hline 6 & $\mathrm{AL}$ & I don't know... \\
\hline
\end{tabular}

R: Researcher

AL: Aliyah (research participant)

Asking a superficial question provided the opportunity to the interviewee to freely reflect the experience for herself. This type of question was used throughout the interviews to assist the participants to mirror on and share their way of experiencing the aspect of the world in context. As Ashworth and Lucas (2000) asserted that the most crucial is the perspective of the interviewee on what the experiences disclose about the aspect of the world understudy. 


\subsection{Strategy 2: Follow up questions focusing on eliciting ideas/concepts}

Excerpt 1 explicates how the researcher framed the probes for the follow up questions, the sorts of comments that were probed and the one that were not explored, the use of meaning-laden phrases (Line 6, Exerpt 2) which was drawn from participants' responses to follow up as well as the recap strategy employed (Line 18-19) to eliminate the possibility of misinterpretation.

Excerpt 2: PBL2 experience from Amal (TISUM PBL2i2)

\begin{tabular}{|c|c|c|}
\hline Line & Speaker & Dialogue \\
\hline $\begin{array}{l}1 \\
2 \\
3 \\
4\end{array}$ & $\mathrm{R}$ & $\begin{array}{l}\text { amal can you please explain... based on your audio transcription referring to page } 9 \text { line } 265 \text { and } 265 \text { and } \\
267 . . .0 \text { key you mentioned that PBL1 susah (difficult)...okey...susah tapi tak (difficult but not) challenging... but } \\
\text { PBL } 2 \text { is challenging...boleh tak (can) you...you explain kenapa susah tapi tak (why difficult but not) } \\
\text { challenging? }\end{array}$ \\
\hline 5 & $\mathrm{AM}$ & urm...er...PBL 1 and PBL2 \\
\hline 6 & $\mathrm{R}$ & $\begin{array}{l}\text { =Aa...yah...PBL } 1 \text { you kata susah (you said difficult)....kenapa (why) you kata susah tapi (said difficult but) not } \\
\text { challenging? }\end{array}$ \\
\hline $\begin{array}{l}7 \\
8\end{array}$ & AM & $\begin{array}{l}\text { Urm...from my opinion, PBL1 is difficult...urm... but not challenging because...urm...I see...urm...the first } \\
\text { time...urm... }\end{array}$ \\
\hline 9 & $\mathrm{R}$ & when you look at it the first time? \\
\hline $\begin{array}{l}10 \\
11\end{array}$ & AM & Urm.... when I look at it...urm...for the first time...I think...the terms and vocabulary... were difficult... \\
\hline 12 & $\mathrm{R}$ & Okey \\
\hline 13 & AM & That...I think was difficult for me... \\
\hline 14 & $\mathrm{R}$ & Oh ok... \\
\hline 15 & AM & But after discussion with friends...ok la \\
\hline 16 & $\mathrm{R}$ & Aha... ok so after discussion it was not difficult \\
\hline 17 & $\mathrm{AM}$ & Aha...coz I understand the task...urrmm PBL1 after discussion \\
\hline $\begin{array}{l}18 \\
19\end{array}$ & $\mathrm{R}$ & $\begin{array}{l}\text { Ok... so what you are saying is PBL } 1 \text { was difficult at your first impression because of the vocabulary in the } \\
\text { task but later... }\end{array}$ \\
\hline 20 & $\mathrm{AM}$ & Aha...yes.. .yes first felt difficult but after discussion easy la \\
\hline 21 & $\mathrm{R}$ & You also said it was not challenging? why \\
\hline 22 & AM & Urm... why... I think my role in this PBL... like marketers. \\
\hline 23 & $\mathrm{R}$ & Okey your role... \\
\hline $\begin{array}{l}24 \\
25\end{array}$ & AM & I imagine I will have to market the product. so, I must do....urm...I must think of the changes to attract mmm \\
\hline 26 & $\mathrm{R}$ & Uhhuh... \\
\hline 27 & AM & So... urm ...to attract the....maybe... maybe to attract the customers... \\
\hline 28 & $\mathrm{R}$ & Uhhuh...so that is not challenging \\
\hline $\begin{array}{l}29 \\
30\end{array}$ & AM & $\begin{array}{l}\text { Tu la (That is why)...I rasa seronok (felt excited) coz boleh (can) imagine and come up with plans to attract the } \\
\text { customers... so tak (not) challenging la tapi seronok (but exciting) }\end{array}$ \\
\hline 31 & $\mathrm{R}$ & Oh ok so you rasa seronok la (felt excited) for PBL1 \\
\hline
\end{tabular}

Excerpt 2 is extracted from a follow up interview to probe some ideas mentioned in an earlier interview. Amar was a bit lost and does not know what to respond when he was asked to share his experience of PBL2. However, eventually he managed to respond after being prompted by the researcher to compare his experience of PBL 1 with that of PBL 2 . Such a technique is of value to the researcher because the participants could respond better since they make out more meaning by comparing one experience to another (Line 1-4, Excerpt 2). There were cautions taken by the researcher in this situation, especially when the participant's comments were not clear by not prompting too much but assisting with verbal cues. This is important to ensure that the participant is given opportunity to think while reflecting. From the excerpt, the opportunity given, made the participant to correct himself in his reflection changing from 'the task being difficult' to 'easy after discussing with his teammates'.

Despite the fact that the participant's should be given enough time to reflect, it is deemed necessary to prompt if there were situation when certain ideas were left unexplained. As in Line 21, Excerpt 2, the researcher had to prompt 
when the participant left the second half of his earlier comment on 'PBL1 was not challenging', unexplained. A backtracking strategy was used with meaning-laden phrases (Line 21, Excerpt 2) to stimulate further comments - But you said PBL1 was difficult but not challenging earlier? The researcher resorted to this strategy to capture and explore the unexplained ideas by ensuring least influence of the researcher's own words or phrases.

Another strategy exercised by the researcher was using a recap. Having heard the explanation from the participant about the confusion and later some clarifications about the same idea, the researcher prompted with a request to recap (Line 18-20, Excerpt 2). It is sensible to ask for a recap if the participant was confused or rather unsure of his ideas so that actual experience is captured. However, there were also times when a recap was done by the researcher in a situation where there was no contradictions in the ideas put forth by the participants.

\subsection{Strategy 3: More follow up questions to get deeper meaning of the ideas/concepts}

In instances where the participant expressed ideas that have potential to elicit deeper meaning, the researcher prompted further asking for more examples or stories that were related to the ideas shared by the research participant. As an illustration from Excerpt 3 (Line 14-19), the participant mentioned that he preferred choosing his own group member for PBL discussion. The researcher prompted further the reasons for his preferences. And from the responses given, the researcher probed for examples or stories from the participant's encounter when he was given a choice to select his own teammates. By this probing technique, the researcher obtained richer data to understand learner's experiences in team works and the reasons behind their choices of selecting group members. However, it is also the decision of the researcher to stop probing when there is a saturation of data (the participant had expressed what he wanted to express). To stop probing, the researcher depended on some criteria. The first criterion used was to stop probing when the researcher felt reasonably comfortable that the interviewee had expressed meaning, even though there might not be a clear boundary of the intended meaning at the moment. There were also other criteria that signaled data saturation; repeated responses, difficulty in explaining when asked for clarifications. Ashworth and Lucas (2000) assert that the criteria discussed above gives clear indication that the researcher can stop probing and that the participants have fully expressed their thoughts on the particular idea.

In strategy 1, 2 and 3 the notion of content-credibility, methodological credibility and communicative credibility are taken care of. It is crucial for the researcher to have a good grasp of the content knowledge so that he or she can demonstrate that during the interviews. As the case in this phenomenographic study, the researcher is well-werse in PBL approach and also the phenomenographic interview paradigm since she has conducted a few series of pilot interviewing prior to the research (Mohd Ali, S., 2012). Booth (1992) states that 'it is is important that this knowledge of the subject matter in question be an open understanding as the 'researcher has to be open for ways of understanding it [the subject matter] which differ from those generally accepted' (p.66). In other words, the need for an 'open understanding' of the subject matter is essential than being a field-specialist. In this study, the intervewing strategies above were employed with openess so that the the participants' voices are captured to the fullest.

Ensuring the credibility of method, the second construct, is related to the context of the interview. Saljo (1996) states that there is a high possibility of 'establishing a joint definition of what is being talked about' in the interview situation (1996, p.23-24) by ensuring a shared experience. Being the participant observer, the researcher managed to use strategy 1, 2 and 3 well, as the researcher has the first-hand experience of the PBL environment and thus, able to understand what is talked about by the participants. In terms of communicative credibility, which is related to the researcher's ability to persuasively put forth a particular explication (Åkerlind, 2005, p.330), the researcher enacted it during the interview. As the discussion in this paper centres on the interviewing strategies, the researcher exercise the communicative credibility by using appropriate phenomenographic interviewing strategies to ensure the data collected reflects the voice of the participants and not mere interpretations of the researcher based on personal experiences. This type of credibility brings to the use of Strategy 4 and Strategy 5 that will be discussed below.

\subsection{Strategy 4: The use of empathy}

Empathy is the capacity to understand what another person is experiencing from within the other person's frame of reference, and to have an understanding of another person's feelings. In phenomenographic interviewing, this aspect is more crucial as the researcher's ability to demonstrate empathy has a strong bearing with the participants' willingness to open up in sharing their experiences.

As Ashworth and Lucas $(2000, p .297)$ mentioned "a paramount requirement for phenomenography is to be sensitive to the individuality of conceptions of the world" clearly portrays that each researcher should be able to 
demonstrate this capability in the interviewing process. In this study, the researcher who played the role of a critical friend to the participants constantly demonstrated empathic attitude during the interviewing sessions. In excerpt 3 (Line 6-12), the researcher tried to make a general statement that each individual is different and it is not wrong to think or feel differently. This is an empathy response used by the researcher to give a sense of comfort to the participant to elicit more responses from the participant who was dissatisfaction with his group members' contribution in the assigned PBL task. In addition, the inability to exercise empathy might lead to the temptation to marginalise certain ideas or experiences from the participants especially if the researcher believes that the views and factual claims as quite untrue. However, the researcher who adopts an attitude of empathy with the participant should find such views and factual claims of deep interest.

\subsection{Strategy 5: Bracketing interviewer's assumptions}

The core interest in the interviews was the meaning conveyed by the participant. Thus, the researcher continuously put aside personal judgment of the ideas presented. As Ashworth and Lucas (2000) asserts that adopting an open and nonjudgemental attitude of the interview responses is a dialectical process which had to be exercised together with the focus on maintaining awareness on the ideas that need further prompts. However, the interviewer should exercise control to a certain extent. In this study, the interviewer played a directive role in the interviews in deciding which of the statements the interviewee has made that require further probing and which do not. Despite the aim of getting more clarifications on certain ideas at the expense of others and there were no attempts to introduce new insights, the researcher is still prone to become prejudice. This is when 'bracketing', a way to detach oneself from the context; should be exercised. In this study, although the researcher had some difficulty in 'bracketing', the probing was done only when certain ideas were not fully unfolded.

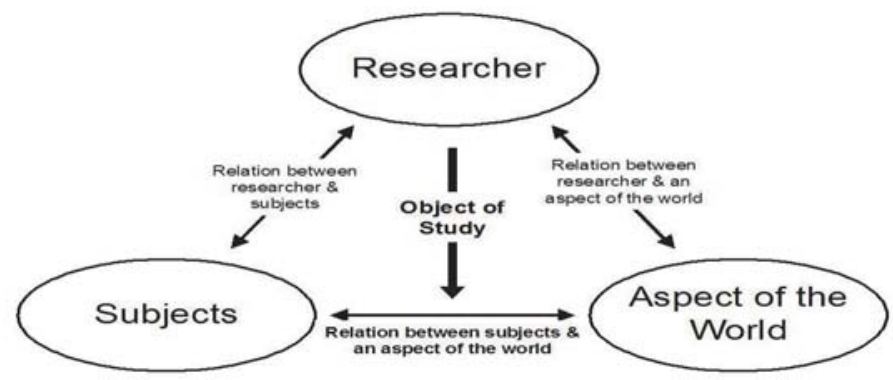

Figure 2: Phenomenographic Research (Bowden, 2005)

Strategies 4 and 5 (Figure 2) are related to the connection among three components namely the interviewees (subjects), the interviewer (researcher), and the object of study that requires the interviewer to position himself away to avoid biasness in the data collection process. In this kind of research, the credibility of method is related to the particular attitude adopted by the researcher in interviews. The kind of attitude as proposed by Booth (1992) 'lies in the researcher's open and thorough attitude, eschewing preconceived ideas and being receptive for the meaning that interviews themselves reveal' ( $p .66)$. It is accepted in the phenomenographic research that the analysis process may differ from one researcher to another; however, the researcher can maintain the methodological credibility by focusing on 'search for meaning' (Booth, 1992). This aspect of credibility is achieved by the researcher by using Strategy 4 and Strategy 5 as discussed above.

\section{Conclusion}

In conclusion, this paper discussed the trustworthiness in a phenomenographic research, specifically on the notion of credibility during the conduct of the phenomenographic interviews. The data illustrations in this paper clearly explicate the five strategies employed by the researcher to tackle the notion of credibility namely content credibility, methodological credibility and communicative credibility, during the data collection stage. The 5 strategies highlighted are: 1) begin with superficially shared topic, 2) follow up questions focusing on eliciting ideas/concepts, 3) more follow up questions to get concrete examples of the ideas/concepts, 4) the use of empathy in the interview and 5) bracketing interviewer's 
assumptions. The strategies employed are in line with the principles of conducting phenomenographic interviews. The first three strategies are related to the probing techniques while the last two are concerned with the attitudes taken by the researcher in conducting the interviews.

\section{References}

Akerlind, G. (2005). Learning about phenomenography: Interviewing data analysis and the qualititative research paradigm. In J. Bowden \& P. Green (Eds.), Doing developmental phenomenography (pp. 63-73). Melbourne: RMIT University Press.

Anderberg, E., Svensson, L., Alvegard, C., Johansson, T. (2008). The epistemological role of language use in learning: A phenomenographic intentional-expressive approach. Educational Research Review, 3(1): 14-29. http://dx.doi.org/10.1016/j.edurev.2007.10.003.

Ashworth, P., \& Lucas, U. (2000). Achieving empathy and engagement: A practical approach to the design, conduct and reporting of phenomenographic research. Studies in Higher Education, 25 (3), 295 - 308.

Bowden, J. (2005). Reflections on the phenomenographic team research process. In J. Bowden \& P.Green (Eds.), Doing developmental phenomenography (pp. 11-31). Melbourne: RMIT University Press.

Collier-Reed, B. I., Ingerman, A., \& Berglund, A. (2009). Reflections on trustworthiness in phenomenographic research: Recognising purpose, context and change in the process of research. Education as Change, 13(2): 339-355.

Devers, K. (1999). How will we know 'good' qualitative research when we see it? Beginning the dialogue in health services research. Health Serv Res, 34 (5 Pt 2): 1153-88.

Edwards, R. and Holland, J., (2013). What is Qualitative Interviewing? London, Bloomsbury, available at http://eprints.ncrm.ac.uk /3276/1/complete_proofs.pdf, accessed 9 Jan 2015.

Mason, J. (2006). Mixing methods in a qualitatively driven way. Qualitative Research 6(1): 9-25.

Mohd Ali, S. (2012). Second Language Learners' Perceptions of a Problem-Based English Course in a Malaysian University. Australia, Melbourne, available at http://arrow.latrobe.edu.au/store/3/5/1/3/5/public/Masterversion.pdf

Roulston, K. (2010). Reflective Interviewing: Guide to Theory and practice. Los Angeles, CA: Sage Publication.

Stenfors-Hayes T, Hult H, Dahlgren L. (2011). What does it mean to be a mentor in medical education? Med Teach, 33 (8):423-8. 